\title{
Children with disabling chronic conditions in the Western health subdistrict of Cape Town, South Africa: Estimating numbers and service gaps
}

\author{
A Redfern, ${ }^{1} \mathrm{MB}$ ChB, MPhil; A Westwood, ${ }^{2} \mathrm{MB} \mathrm{ChB}, \mathrm{MMed}, \mathrm{MD}$; K A Donald, ${ }^{3} \mathrm{MB} \mathrm{ChB}, \mathrm{MPhil}, \mathrm{PhD}$ \\ ${ }^{1}$ Department of Paediatrics and Child Health, Tygerberg Children's Hospital, Faculty of Medicine and Health Sciences, \\ Stellenbosch University, Cape Town, South Africa \\ ${ }^{2}$ School of Child and Adolescent Health, Faculty of Health Sciences, University of Cape Town, and General Paediatrics, \\ Metro West, Department of Health, Provincial Government of the Western Cape, Cape Town, South Africa \\ ${ }^{3}$ Division of Developmental Paediatrics, Department of Paediatrics and Child Health, Red Cross War Memorial Children's \\ Hospital, University of Cape Town, South Africa
}

Corresponding author: A Redfern (redfern@sun.ac.za)

\begin{abstract}
Background. Children with disabling chronic conditions often have extensive, complex and unmet healthcare and educational needs. They can be defined as a subset of the group of children with chronic health conditions whose condition results in some degree of functional or activity limitation. There is limited information in South Africa and other low- and middle-income countries with regard to the percentage of such children that access specialist health and special educational services, particularly in an urban setting, and what services exist for them. Objectives. To count the number of children with disabling chronic conditions who were accessing specialist health and special educational services in the Western health subdistrict of Cape Town, and to briefly describe the access to services outside of hospital-based specialist services. Methods. A cross-sectional observational study was conducted between January 2010 and December 2011. The target population included all children $<19$ years of age with disabling chronic conditions, living in the Western subdistrict of Cape Town, who were accessing specialist health and special educational services. Such children were identified from the relevant referral hospitals, educational institutions, and private and non-profit organisations in the area.

Results. A total of 1138 children with disabling chronic conditions were identified. In the context of an under-19 population of 112249 , this corresponds to a rate of 10 per 1000 , whereas the expected rate of children with disabling chronic conditions would be about 50 per 1000 . Only $14 \%$ of children in special educational institutions attended specialist paediatric services during a 2 -year period. Allied health and medical services for children outside of hospitals were very limited.

Conclusions. There are a significant number of children with disabling chronic conditions who do not access health and special educational services in the Western health subdistrict of Cape Town. Medical and allied health support for children in institutions is very limited. Current information systems are inadequate to describe the need.
\end{abstract}

S Afr Med J 2016;106(3):302-307. DOI:10.7196/SAMJ.2016.v106i3.9825

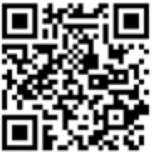

Children with disabling chronic conditions represent a vulnerable subset of the childhood population whose medical, social and educational needs are diverse and complex. ${ }^{[1]}$ These children can be defined as a subset of the group of children with chronic health conditions whose condition results in some degree of functional or activity limitation. It is well known that children with chronic conditions frequently have unmet needs and do not access the health and educational services essential to their wellbeing. ${ }^{[2]}$ In the USA, $16.2 \%$ of children with chronic health conditions had unmet therapeutic service needs (such as allied health professional therapies) and $9.8 \%$ had unmet supportive service needs (such as equipment, transport, respite care) ${ }^{[3]}$ In this group, children with a disabling chronic condition were especially vulnerable.

The situation in low- and middle-income countries (LMICs) is almost certainly worse. However, research on children with disabling chronic conditions in such countries is largely lacking, focuses predominantly on epidemiological studies, and is generally of poor scientific quality. ${ }^{[4]}$ In South Africa (SA), scarce information exists with regard to the prevalence of childhood disability or chronic conditions, access to services, or effectiveness of interventions. ${ }^{[5-7]}$ Most studies describe rural or peri-urban populations. ${ }^{[8,9]}$ Rapid urbanisation and improving under-5 mortality rates are likely to result in an increased prevalence of these children in urban areas, placing a significant burden on already stretched health and educational services.

For the majority of children with disabling chronic conditions, their package of care would include specialist paediatric services or access to a special educational institution. It is not known what percentage of these children access specialist services. Services for these children outside of the hospital setting are not well described. Lack of information with regard to the number of children with disabling chronic conditions and the health and educational services they access, negatively affects service planning.

\section{Objectives}

The purpose of this study was to count the number of children with disabling chronic conditions who access specialist healthcare facilities or special needs educational services in an urban metro subdistrict. It was assumed, for the purposes of this study, that the majority of such children would access specialist paediatric health or special educational services at least once during a 2-year period. A second objective was to describe the access to services outside of the hospital setting. 


\section{Methods}

A cross-sectional survey was conducted over a 2-year period between January 2010 and December 2011. The target population comprised children $<19$ years with disabling chronic conditions, residing in the Western subdistrict, who accessed specialist services (Fig. 1). Multiple sources of information were consulted to identify as many access points as possible for children with such conditions. These included hospitals, educational institutions for children with special needs, and relevant for-profit organisations (FPOs) and non-profit organisations (NPOs) that provide services to children with chronic disabling conditions and their families.

Data were collected from the hospitals that provide specialist outpatient or inpatient services for the subdistrict. It was not possible to obtain information from districtand community-based services, as their information systems did not capture these data. Data from all sources were entered into an electronic database, and duplicates were identified and removed.

The tertiary referral hospital (Red Cross War Memorial Children's Hospital (RCWMCH)) had an electronic patient administration system containing International Classification of Disease (ICD)-10 codes. Two years of admissions/outpatient attendances were captured (January 2010 December 2011). Predominantly neurological, neurodevelopmental and genetic conditions were considered. Chronic conditions likely to have a fairly inevitable progression towards some limitation of activity or functional ability were included. Children with a chronic health condition that would not definitely result in some form of disability were excluded. A list of the clinics and ICD10 codes are given in Appendix 1.

The regional referral hospital for the subdistrict, New Somerset Hospital (NSH), did not have an adequate ICD-10 record in its electronic patient administration system. Consequently, children with disabling chronic conditions were identified by a single paediatrician in the second year through ward admissions or the general paediatric outpatient clinic.

RCWMCH and NSH paediatric services only attended to children $\leq 13$ years, although children known to have chronic conditions stayed in the paediatric services longer before being transferred owing to the lack of adequate adolescent services.

Educational institutions were identified through the 2011 Directory of Services for Children with Special Needs in the Cape Town Area booklet ${ }^{[10]}$ and through communication with the heads of Special

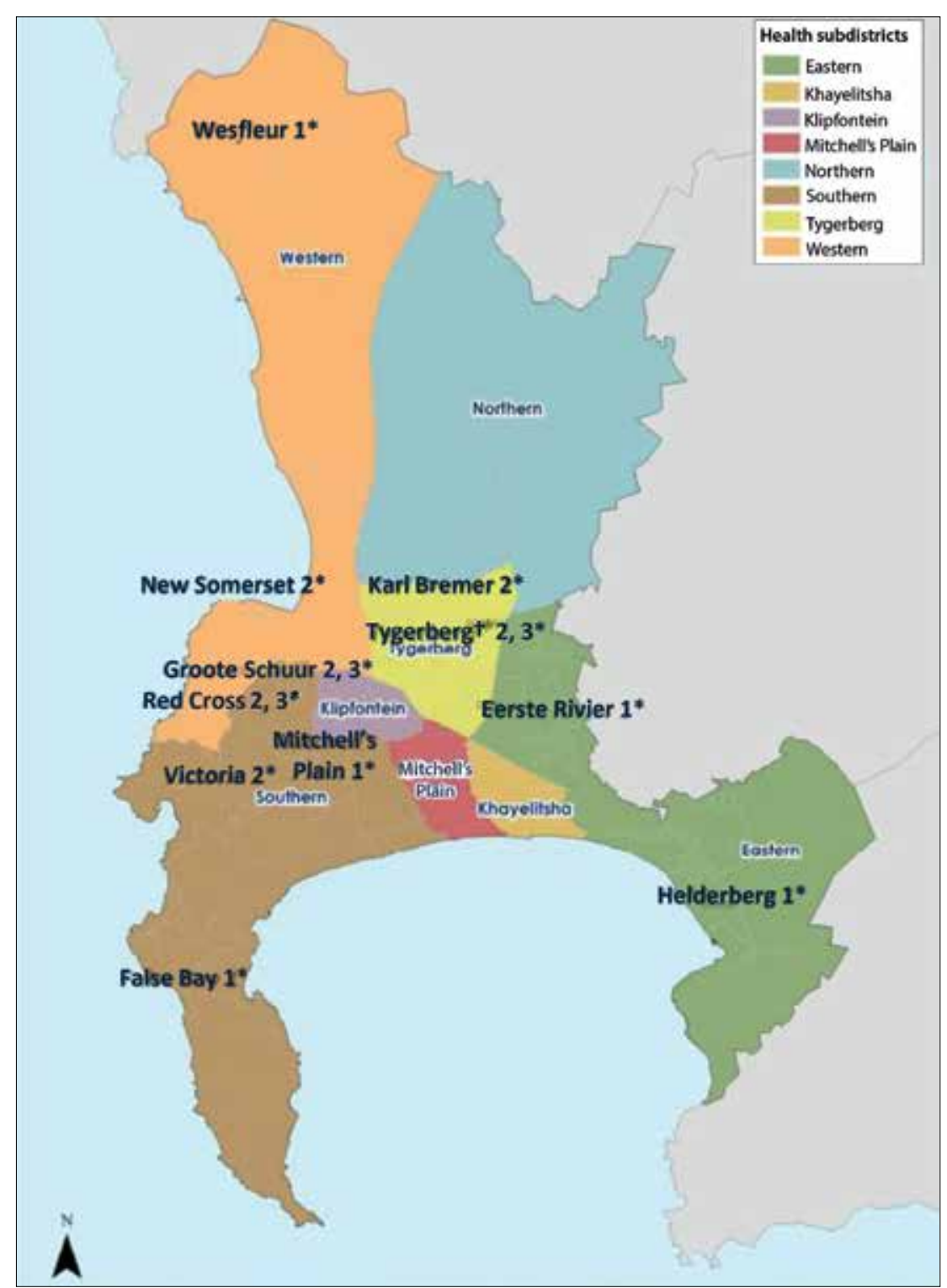

Fig. 1. Map of health subdistricts in the Cape Town metropole. $\left({ }^{*}\right.$ Hospital and level of care. ${ }^{\dagger}$ Includes Khayelitsha District Hospital, level 1.)

Education for the relevant Western Cape Education Department district offices. The educational institutions generally catered for children with moderate to severe intellectual disability, cerebral palsy or autism spectrum disorders. They were characterised as either special schools or special care centres (SCCs), depending on the type of institution and educational curriculum. It was assumed, for the purposes of this study, that children in these institutions were appropriately placed.

Institutions were requested to provide details of children in their facility and identify the number of children attending hospital appointments at one of the referral hospitals. Furthermore, respondents completed a questionnaire outlining their staff details and the number of sessions/posts each institution had with regard to allied health professionals and medical support. Facility managers provided a subjective assessment of the care needs of the children in their institutions with regard to mobility, toileting and feeding.

Permission was obtained from the hospitals to access their electronic patient information systems, and ethical approval was obtained from the University of Cape Town Health Research Ethics Committee prior to commencement (HREC 425/2011). Statistical analysis of the combined final dataset was done using Microsoft Excel 2011.

\section{Results}

A total of 1138 children with chronic disabling conditions accessed specialist paediatric services or special educational institutions. Table 1 details the sources through which 
these children were identified - the majority from the tertiary referral hospital or educational institutions. Only one NPO returned information (Autism Western Cape), despite several NPOs from the developmental/disability sector being contacted. The only FPO that was asked for information was Vitalaire, which provides home oxygen to all children in the metro who require it. Only one child on their database was from the Western subdistrict.

For 858 children name, age and sex were available. The mean age of this group was 8.1 years ( 3 months - 18.6 years). There was a male predominance (male:female ratio of 1.4:1).

Only $14 \%$ of children in educational facilities attended specialist services at one of the referral hospitals. This information was acquired by analysing the hospital and non-hospital data sets for duplicates, or by contacting the facility managers/principals when demographic information was unavailable. Children with physical disability and no significant intellectual disability were more likely to attend specialist services $(22 \%)$ than those with moderate $(2.5 \%)$ or severe $(11 \%)$ intellectual disability.

Table 2 outlines the proportion of children from the Western subdistrict in the respective educational institutions. The SCCs were on average at $82.6 \%$ of capacity, and special schools at $95.7 \%$ of capacity.

Three SCCs and one special school provided information on the care needs of 159 children (Figs 2 and 3). As expected, children in

\section{Table 1. Children identified through various sources of} information, $n$

\begin{tabular}{ll}
\hline Source & \\
\hline Tertiary referral hospital (RCWMCH) & 545 \\
Secondary referral hospital (NSH) & 14 \\
Special care centres $(n=4)$ & 162 \\
Special schools $(n=8)$ & 395 \\
Autism Western Cape (NPO) & 27 \\
Vitalaire (FPO) & 1 \\
Total & 1138
\end{tabular}

the SCCs were less independent than those in special schools. The majority of children in SCCs were either partially or fully dependent for feeding and mobility. In special schools, only $22 \%$ and $11 \%$ were dependent for feeding or mobility, respectively. In the SCCs $75 \%$ of children were either partially or fully dependent for toileting, compared with $28 \%$ of children in the special schools.

\section{Table 2. Children from the Western subdistrict in special} educational institutions

\begin{tabular}{|c|c|c|c|}
\hline Institution & $\begin{array}{l}\text { Western sub- } \\
\text { district, } n\end{array}$ & $\begin{array}{l}\text { Total currently } \\
\text { in school, } n\end{array}$ & $\begin{array}{l}\text { School capacity, } \\
n(\%)\end{array}$ \\
\hline \multicolumn{4}{|c|}{ Special care centres } \\
\hline Wilge & 23 & 30 & $30(100.0)$ \\
\hline Friends & 73 & 112 & $120(93.3)$ \\
\hline Emmanuel & 36 & 47 & $75(62.7)$ \\
\hline Elundini & 30 & 30 & $40(75.0)$ \\
\hline $\begin{array}{l}\text { Joe Slovo/ } \\
\text { Ukwanda }\end{array}$ & - & - & - \\
\hline Total & 162 & 219 & $265(82.6)$ \\
\hline \multicolumn{4}{|l|}{ Special schools } \\
\hline Molenbeek & 123 & 164 & $165(99.4)$ \\
\hline Peter Pan & 18 & 60 & $70(85.7)$ \\
\hline Dawn & 214 & 233 & $233(100.0)$ \\
\hline $\begin{array}{l}\text { SEAL } \\
\text { College }\end{array}$ & 14 & 14 & $14(100.0)$ \\
\hline $\begin{array}{l}\text { Athlone } \\
\text { School for } \\
\text { the Blind }\end{array}$ & 6 & 420 & $450(93.3)$ \\
\hline Vista Nova & 12 & 440 & $480(91.7)$ \\
\hline $\begin{array}{l}\text { Mountain } \\
\text { View }\end{array}$ & 8 & - & - \\
\hline Filia & - & 182 & $182(100.0)$ \\
\hline Total & 395 & 1513 & $1594(95.7)$ \\
\hline
\end{tabular}

Table 3. Health professionals (full time or days per month, $n$ ) in educational institutions

\begin{tabular}{|c|c|c|c|c|c|c|}
\hline Institution & Physiotherapist & Occupational therapist & Speech language therapist & Doctor & Psychologist & Nurse/sister \\
\hline \multicolumn{7}{|l|}{ Special care centres } \\
\hline Wilge & 2 days/year & 1 & 4 & 4 days/year & 0 & FT (1) \\
\hline Friends & 3 & 0 & 0 & 0 & 0 & 0 \\
\hline Emmanuel & 2 & 2 & 0 & 0 & 0 & 0 \\
\hline Elundini & 0 & 0 & 0 & 0 & 0 & 0 \\
\hline \multicolumn{7}{|l|}{ Special schools } \\
\hline Molenbeek & 0 & 1 & 0 & 0 & 0 & 0 \\
\hline Peter Pan & FT (1) & FT (1) & FT (1) & Yes & 0 & FT (1) \\
\hline Dawn & 0 & FT (1) & 0 & 0 & 0 & 0 \\
\hline SEAL College & 4 & 0 & 4 & 0 & 0 & 0 \\
\hline $\begin{array}{l}\text { Athlone School } \\
\text { for the Blind }\end{array}$ & FT (1) & FT (5) & 0 & 0 & FT (3) & FT (1) \\
\hline Vista Nova & FT (4) & FT (4) & FT (3) & Yes & FT (1) & FT (1) \\
\hline Filia & FT (1) & FT (2) & 0 & 2 days/quarter & 4 & FT (1) \\
\hline
\end{tabular}




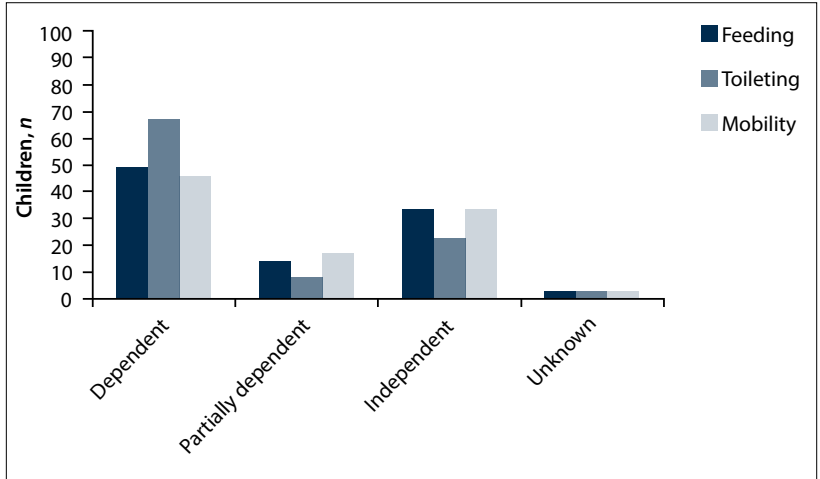

Fig. 2. Care needs of children in special care centres.

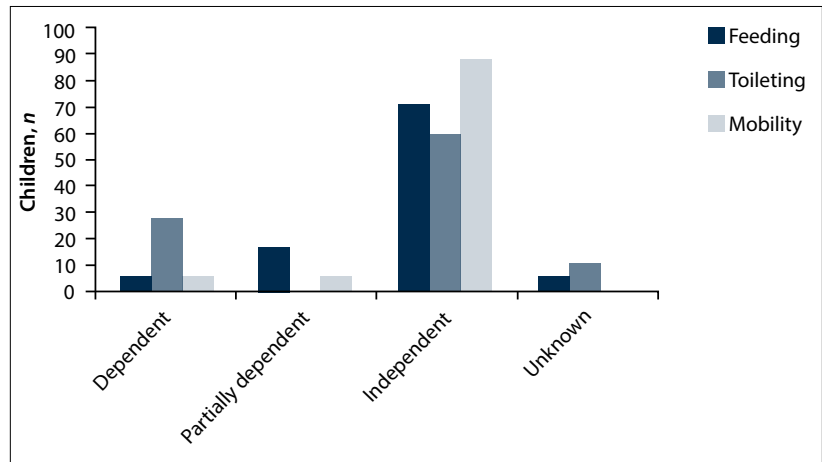

Fig. 3. Care needs of children in special schools.

The availability of health professional services for children in educational institutions is detailed in Table 3. SCCs generally had very limited support from allied health professionals (physiotherapists, occupational therapists and especially speech therapists). There was a great deal of variation in terms of the amount of allied health professional support between the various special schools. Some schools had very little allied health professional input. Five of the seven special schools had at least one full-time therapist. The allied health professional subgroup most poorly represented overall was speech and language therapists.

Medical support (doctors, nurses and psychologists) was extremely limited at the SCCs and special schools. Only one SCC received any direct medical support in the form of a full-time nursing sister and a paediatrician who visited quarterly. The medical support at special schools varied considerably. Schools for children with intellectual disability had no medical support, while those that catered for children with other or multiple disabilities had nursing and psychological support, and varying degrees of support from a doctor.

\section{Discussion}

This study describes the number of children with disabling chronic conditions in the Western subdistrict who access specialist health and educational services. Robust epidemiological data are not available for such children in SA, and especially in urban settings, where access to care is likely to be greater. The rationale behind our methodology was the assumption that the majority of children with disabling chronic conditions in an urban setting would access specialist paediatric or special educational services at least once in a 2 -year period. A total of 1138 children were identified. At the time of the study, the total population of children $<19$ years living in the Western subdistrict of Cape Town was 112 249, based on 2011 census data (Hendricks M, et al. A situation analysis of neonatal and child health status in the metro West geographic service area of the Western Cape - unpublished report, 2012). This corresponds to a rate of 10 per 1000 population.

The first notable finding therefore is how few children were identified, despite extensive efforts to gain information from as many sources as possible. To put this in perspective, the World Health Organization (WHO) suggests a global prevalence figure of 51 per 1000 for moderate to severe disability. ${ }^{[1]}$ This is probably a realistic figure as comparison, because the current study was biased towards identifying children with moderate to severe disability. In SA, previous prevalence estimates ranged from 43 to 60 per 1000 for overall disability. ${ }^{[8,11]}$ This suggests that a significant number of children were either not identified, or do not access healthcare.

Despite the relatively small number of children identified, it is noteworthy that further capacity in special educational institutions in the subdistrict is very limited, with most institutions having $>90 \%$ of places filled. It has been reported previously that a significant number of children who require special schooling are not in special schools owing to lack of capacity. ${ }^{[12]}$ Our study supports this finding. SA mainstream schools should be creating a more inclusive environment for children with special needs, but the necessary support and remedial structures are not in place in the majority of schools. Inadequate screening, paucity of educational psychologists and lack of viable alternatives mean that many children with milder disabilities are likely to be struggling along in mainstream schools. ${ }^{[9]}$

The majority of children placed in special educational institutions do not attend specialist healthcare services. This is understandable considering the relatively low rate of medical comorbidities in intellectual disability. However, even among children with physical disability, or children with multiple disabilities, $80-90 \%$ were not attending specialist healthcare services. This is concerning when one notes the very limited amount of therapeutic and medical support provided in specialist educational institutions, despite these children having substantial care needs.

A number of factors need to be considered when questioning why so few children were identified. The study design aimed to identify children accessing health facilities or special educational institutions. It is likely that a significant number of children with disability do not access the health or education systems in SA. ${ }^{[13]}$ Two possible reasons are given, i.e. a perception that it is useless to offer care or education to a disabled child; or a desire to avoid the stigma of taking a disabled child into public areas such as a school or hospital. ${ }^{[14]}$ Other practical reasons, such as lack of adequate transport or finances to reach a hospital, may prevent disabled children from accessing care or schools. The number of children who are cared for in their homes or use community-based services is unknown - they were not counted in this study.

Sociocultural factors may also play a role. ${ }^{[13,15]}$ Extended families are important in the raising of children, particularly in African cultures. One of the driving forces of urbanisation is employment seeking by young adults, and often extended families remain in rural areas while the younger generation work in the city. Consequently, many children with disabling chronic conditions may be sent to live with extended family in rural areas to allow the parents to continue working, thereby reducing the prevalence in urban areas. This phenomenon has been described among families affected by HIV. ${ }^{[15]}$

The Western subdistrict has some of the best economic and health indicators in SA. ${ }^{[16]}$ Low unemployment rates, high immunisation rates, and a very successful prevention of mother-to-child transmission of HIV programme are some of the factors that may reduce the burden of childhood disability in the region. (Hendricks M, et al. A situation analysis of neonatal and child health status in the metro West geographic 
service area of the Western Cape - unpublished report, 2012). Access to specialist care is relatively good in the subdistrict, which made this an appropriate methodology for our study. The findings highlight the lack of capacity in special educational services, both in terms of number of places and allied health and medical support. Our study also highlights the inadequacy of current information systems to clearly estimate the size of the problem. These findings are generalisable to other parts of SA and other LMICs, where the situation may even be worse.

There are several limitations to this study. Firstly, owing to its crosssectional nature, it relied on ICD-10 codes, which will miss a number of children as a result of incorrect coding of patients, poor use of secondary codes and failure of staff to complete coding. Secondly, this study focused mainly on specialist healthcare services and special educational institutions. The lack of information from primary healthcare and community sources may have resulted in a number of children being missed from this count. Thirdly, information from a number of educational institutions was not available owing to the lack of availability of the required information or a lack of response.

\section{Conclusions}

Despite the limitations of this study, the fact that a significant number of children with chronic disabling conditions are 'missing', i.e. not accessing health and special educational services, is demonstrated. A lack of chronic care services for children in the healthcare system and an insufficient number of services and facilities for children with special educational needs are likely to be contributing factors. This study also shows that the current information systems are inadequate and unreliable for identifying the burden of children with disabling chronic conditions. Information systems need to be significantly improved to plan for services. Intersectoral collaboration between educational and health sectors is crucial to promote inclusivity and integration and avoid that these children fall through the cracks.

Larger-scale prevalence studies are needed to facilitate health and educational service planning. There is a need to develop and capacitate the healthcare system for the care of children with chronic conditions, and an urgent need to capacitate the special educational services available to children. Further studies need to be conducted in SA and other LMICs to establish whether these findings are replicable in other contexts.

\section{References}

1. World Heath Organization. World report on disability, 2011. http://whqlibdoc.who.int/ publications/2011/9789240685215_eng.pdf (accessed 5 December 2013).

2. Carnevale F, Rehm RS, Kirk S, et al. What we know (and do not know) about raising children with complex continuing care needs. J Child Health Care 2008;12(1):4-6. [http://dx.doi. org/10.1177/1367493508088552]

3. Benedict RE. Quality medical homes: Meeting children's needs for therapeutic and supportive services. Pediatrics 2008;121(1):e127-e34. [http://dx.doi.org/10.1542/peds.2007-0066]

4. Maulik PK, Darmstadt GL. Childhood disability in low- and middle-income countries: Overview of screening, prevention, services, legislation, and epidemiology. Pediatrics 2007;120:S1-S55. [http://

5. Saloojee G, Phohole M, Saloojee $\mathrm{H}$, et al. Unmet health, welfare and educational needs of Saloojee G, Phohole M, Saloojee H, et al. Unmet health, welfare and educational needs of
disabled children in an impoverished South African peri-urban township. Child Care Health Dev disabled children in an impoverished South African peri-urban townsh
2007;33(3):230-235. [http://dx.doi.org/10.1111/j.1365-2214.2006.00645.x]

2007;33(3):230-235. [http://dx.doi.org/10.1111/j.1365-2214.2006.00645.x]
6. Department of Social Development. Strategy for the Integration of Services for children with disabilities. 2009. http://www.ruralrehab.co.za/uploads/3/0/9/0/3090989/strategy_integr_services_ cwd_dsd_2009.pdf (accessed 5 December 2013).

7. Guthrie T. Disability and Chronic Illness Prevalence in Children in South Africa. Committee of Inquiry into a Comprehensive Social Security System in South Africa. Rondebosch: Child Health Policy Institute, 2001.

8. Couper J. Prevalence of childhood disability in rural KwaZulu-Natal. S Afr Med J 2002;92(7):549-552.

9. Giarelli E, Clarke D, Catching C, Ratcliffe S. Developmental disabilities and behavioral problems among school children in the Western Cape of South Africa. Res Dev Disabil 2009;30(6):1297-1305. [http://dx.doi.org/10.1016/j.ridd.2009.05.006]

10. Child Care Information Centre. Directory of Services for Children with Special Needs in the Cape Town Area. Rondebosch: University of Cape Town, 2011.

11. Kromberg J, Zwane E, Manga P, et al. Intellectual disability in the context of a South African population. Journal of Policy and Practice in Intellectual Disabilities 2008;5(2):89-95. [http://dx.doi. org/10.1111/j.1741-1130.2008.00153.x

12. Ministry of Education. Education White Paper 6 Special Needs Education: Building an Inclusive Education and Training System. Pretoria: Department of Education, 2001. http://www.education.gov. za/LinkClick.aspx?fileticket=gVFccZLi/tI $=($ accessed 26 September 2013).

13. Donald K, Samia P, Kakooza-Mwesige A, et al. Pediatric cerebral palsy in Africa: A systematic review. Semin Pediatr Neurol 2014;21:30-35.

14. Tallawy E, Farghaly W, Metwaly N, et al. Door to door survey of major neurological disorders in A Kharga District, New Valley, Egypt: Methodological aspects. Neuroepidemiol 2010;35(3):185-190.

15. Hosegood V, Ford, K. The impact of HIV/AIDS on children's living arrangements and migration in rura South Africa. 2003. http://www.childmigration.net/files/3-Hosegood.pdf (accessed 2 February 2014).

16. City of Cape Town. 2011 Census. Western Health District. http://www.capetown.gov.za/en/stats/2011 Census Health District Profiles/Western Health District.pdf (accessed 2 February 2014).

Accepted 22 January 2016.

\begin{tabular}{|c|c|c|c|}
\hline \multicolumn{4}{|l|}{ Clinics } \\
\hline \multicolumn{4}{|l|}{ Neuromuscular } \\
\hline \multicolumn{4}{|l|}{ Neurodevelopmental } \\
\hline \multicolumn{4}{|l|}{ Spinal defects } \\
\hline \multicolumn{4}{|l|}{ Cerebral palsy } \\
\hline \multicolumn{4}{|l|}{ Relevant ICD-10 codes } \\
\hline Condition & ICD-10 & Condition & ICD-10 \\
\hline Cerebral palsy: ataxic & G80.4 & Neuronal migration disorder & Q04.3 \\
\hline Cerebral palsy: athetoid & G80.3 & Schizencephaly & Q04.6 \\
\hline Cerebral palsy: choreoathetoid & G80.3 & Cervical spina bifida with hydrocephalus & Q05.1 \\
\hline Cerebral palsy: diplegic & G80.1 & Thoracic spina bifida with hydrocephalus & Q05.2 \\
\hline Cerebral palsy: dystonic & G80.3 & Lumbar spina bifida with hydrocephalus & Q05.3 \\
\hline Cerebral palsy: hemiplegic & G80.2 & Spina bifida with hydrocephalus & Q05.4 \\
\hline Cerebral palsy: hypotonic & G80.8 & Cervical spina bifida without hydrocephalus & Q05.5 \\
\hline Cerebral palsy: quadriplegic & G80.0 & Thoracic spina bifida without hydrocephalus & Q05.6 \\
\hline Cerebral palsy: triplegic & G80.8 & Lumbar spina bifida without hydrocephalus & Q05.7 \\
\hline Cerebral palsy: unspecified & G80.9 & Sacral spina bifida without hydrocephalus & Q05.8 \\
\hline \multirow[t]{2}{*}{ Deafness } & H91.9 & Hypoplasia and dysplasia of spinal cord & Q06.1 \\
\hline & & & tinued .. \\
\hline
\end{tabular}




\begin{tabular}{|c|c|c|c|}
\hline \multicolumn{4}{|l|}{ Relevant ICD-10 codes } \\
\hline Condition & ICD-10 & Condition & ICD-10 \\
\hline Blindness & H54.7 & Diastematomyelia & Q06.2 \\
\hline Mental retardation, moderate (IQ 35 - 49) & F71.9 & Anophthalmos & Q11.1 \\
\hline Mental retardation, severe (IQ 20 - 34) & F72.9 & Tracheostomy care & Z43.0 \\
\hline Mental retardation, profound (IQ <20) & F73.9 & Tracheostomy malfunction & J95.0 \\
\hline Autism & F84.0 & Tracheostomy present & Z93.0 \\
\hline Development, pervasive developmental disorder & F84.9 & Myasthenia, congenital & G70.2 \\
\hline Pervasive developmental disorders & F84.9 & Duchenne muscular dystrophy & G71.0 \\
\hline Huntington's disease & G10.X & Dystrophia myotonica & G71.1 \\
\hline Friedreich's ataxia & G11.1 & Congenital muscular dystrophy & G71.2 \\
\hline Ataxia telangiectasia & G11.3 & Mitochondrial myopathy & G71.3 \\
\hline Spinal muscular atrophy, type 1 & G12.0 & Myopathy, congenital & G71.9 \\
\hline Spinal muscular atrophy, type 2 or 3 & G12.1 & Myopathy, other, specified & G72.8 \\
\hline Mitochondrial disorder & G31.8 & Myelomeningocoele & Q05.9 \\
\hline Brain, degenerative disease & G31.9 & Holoprosencephaly & Q04.2 \\
\hline Epilepsy, Lennox-Gastaut syndrome & G40.4 & Brain damage, post meningitis & G09.X \\
\hline Spinocerebellar degeneration & G11.8 & Huntington's disease & G10.X \\
\hline Basal ganglia, degenerative disease & G23.8 & Hereditary spastic paraplegia & G11.4 \\
\hline Multiple sclerosis & G35.X & Opsoclonus myoclonus & G24.8 \\
\hline Acute transverse myelitis & G37.3 & Dystonia & G24.9 \\
\hline Hereditary motor and sensory neuropathy & G60.0 & HIV infection, encephalopathy & B22.0 \\
\hline Intellectual disability & F79.9 & Friedreich's ataxia & G11.1 \\
\hline Ataxia, hereditary & G11.9 & Trisomy 21 & Q90.9 \\
\hline Hereditary spastic paraplegia & G11.4 & & \\
\hline
\end{tabular}

